\title{
Malondialdehyde mediates oxidized LDL-induced coronary toxicity through the Akt-FGF2 pathway via DNA methylation
}

\author{
Tzu-Ching Yang ${ }^{1}$, Yi-Jie Chen ${ }^{1}$, Shwu-Fen Chang ${ }^{2}$, Chu-Huang Chen ${ }^{3,4,5}$, Po-Yuan Chang ${ }^{6 *}$ and Shao-Chun Lu ${ }^{1}$
}

\begin{abstract}
Background: Oxidized LDL (oxLDL) is involved in the development of atherosclerotic heart disease through a mechanism that is not fully understood. In this study, we examined the role of malondialdehyde (MDA), an important oxidative stress epitope of oxLDL, in mediating coronary endothelial cytotoxicity.

Results: Human coronary artery endothelial cells (HCAECs) were treated with oxLDL in the presence or absence of antibody against MDA (anti-MDA) or apoB100 (anti-apoB100). In HCAECs treated with oxLDL $(100 \mu \mathrm{g} / \mathrm{ml}$ ) alone, DNA synthesis, cell viability, and expression of prosurvival fibroblast growth factor 2 (FGF2) were significantly reduced $(P<0.01$ vs phosphate buffered saline-treated cells). These inhibitory effects of oxLDL were significantly attenuated in HCAECs cotreated with anti-MDA $(0.15 \mu \mathrm{g} / \mathrm{ml} ; P<0.05$ vs oxLDL-treated cells), but not in those cotreated with anti-apoB100. When we tested the effects of a panel of signal transduction modifiers on the signal transduction pathways of MDA in oxLDL-treated HCAECS, we found that MDA-induced cytotoxicity was mediated partly through the Akt pathway. Using a reporter gene assay, we identified an oxLDL-response element in the FGF2 promoter that was responsible for the transcriptional repression of FGF2 by oxLDL. The results of bisulfite genomic DNA sequencing showed that in HCAECs treated with oxLDL, the GC-rich promoter of FGF2 was heavily methylated at cytosine residues, whereas cotreatment with anti-MDA markedly reduced oxLDL-induced FGF2 promoter methylation.
\end{abstract}

Conclusion: OxLDL disrupts the growth and survival of HCAECs through an MDA-dependent pathway involving methylation of the FGF2 promoter and repression of FGF2 transcription. This novel epigenetic mechanism of oxLDL may underlie its atherogenicity in patients with atherosclerotic cardiovascular disease.

Keywords: DNA methylation, Epigenetics, Gene expression, Lipid oxidation, Lipoproteins, Malondialdehyde (MDA), Signal transduction

\section{Background}

Oxidized low-density lipoprotein (oxLDL) has been shown to accumulate in atherosclerotic lesions, and a growing body of evidence indicates that oxLDL is involved in the pathogenesis of coronary artery disease, acute coronary syndrome, and vulnerable plaque [1]. Experimentally, oxLDL exposure induces a variety of effects in endothelial cells (ECs), such as the release of chemokines, cytokines, and growth factors; the expression of surface molecules

\footnotetext{
* Correspondence: pychang@ntu.edu.tw

${ }^{6}$ Cardiovascular Center and Division of Cardiology, Department of Internal Medicine, National Taiwan University Hospital and College of Medicine, No. 7, Chung-Shan South Road, Taipei 100, Taiwan

Full list of author information is available at the end of the article
}

that regulate endothelial permeability and hemostatic properties; and changes in cell growth, division, and death $[2,3]$. The pathophysiologic effects of oxLDL observed in vitro have been implicated in the initiation and progression of atherosclerosis in vivo [4].

Malondialdehyde (MDA) is an end-product of the radical-initiated oxidative decomposition of polyunsaturated fatty acids; therefore, it is frequently used as a biomarker of oxidative stress [5]. Clinical data have indicated that MDA-type epitopes are prominent and prevalent and are important in cardiovascular disease; thus, these antigens are key candidates for use in characterizing immune responses that are relevant to atherosclerosis [6,7]. The Veterans Affairs Diabetes Trial, a recent clinical trial that 
investigated the association between MDA and diabetes mellitus, showed that the levels of MDA-LDL in circulating immune complexes can predict the occurrence of myocardial infarction and acute cardiovascular events in patients with type 2 diabetes [8]. However, the precise mechanism by which MDA might be causing endothelial cytotoxicity is not known.

OxLDL has suppressive effects on genes that regulate endothelial function, such as nitric oxide synthase [9]. Furthermore, oxLDL can modulate the signal transduction pathway of receptor $\mathrm{Gi}$ coupling by downregulating the expression of heterotrimeric G protein Gai2 [10]. In addition, we have previously shown that the endothelial damage caused by oxLDL is accompanied by the selective downregulation of fibroblast growth factor 2 (FGF2) and can be prevented by supplementing cells with exogenous FGF2 [11,12]. Using an in vitro model of angiogenesis, we also showed that capillary-like microtube growth was impaired in arterial explants from hypercholesterolemic rabbits or in those from normocholesterolemic rabbits exposed to oxLDL in vitro and that this reduced microtube growth was associated with reduced FGF2 concentrations in the culture medium of the explants [13]. The downregulation of FGF2 expression, therefore, has become a recognized mechanism of endothelial dysfunction.

FGF2 is a pleiotropic protein that regulates a wide range of functions and has angiogenic and anti-apoptotic effects on vascular ECs $[14,15]$. The reduction of FGF2 levels in ECs has detrimental effects, such as massive apoptosis and greatly impaired angiogenic responses [13]. When ECs are treated with homocysteine, FGF2 is downregulated at the transcriptional level by a mechanism involving DNA methylation of the GC-rich FGF2 promoter [16]. However, how oxLDL and its oxidative stress epitopes, such as MDA, regulate transcription of FGF2 is not known. In this study, we examined the role of MDA in mediating coronary endothelial cytotoxicity and addressed the question of whether oxLDL downregulates endothelial FGF2 via a signaling pathway that involves DNA methylation. We have identified a mechanistic model of EC gene modulation influenced by oxLDL and MDA epitopes.

\section{Methods}

\section{Cells and preparation of LDL}

Human coronary artery ECs (HCAECs, Clonetics, USA) were maintained from passages 4 to 7 in microvascular endothelial cell growth medium (EGM-MV) supplemented with $20 \%$ fetal bovine serum and antibiotics $(100 \mathrm{\mu g} / \mathrm{ml}$ streptomycin, $100 \mathrm{IU} / \mathrm{ml}$ penicillin, and $0.25 \mu \mathrm{g} / \mathrm{ml}$ amphotericin B). Oxidized LDL was prepared as previously described [11,12], and precautions were taken to prevent endotoxin contamination. The protein concentration of each LDL preparation was determined by using the Lowry method, and thiobarbituric acidreactive substances (TBARS) were determined as a measure of oxidative lipid modification [11,12].

\section{DNA synthesis analysis, cell counting, and enzyme-linked immunosorbent assay (ELISA)}

For the DNA synthesis and intracellular FGF2 protein assays, HCAECs $\left(1 \times 10^{6}\right)$ were seeded in each well of 12 well Corning cell culture plates (Corning, USA). HCAECs were incubated for 24 hours with or without oxLDL $(100 \mu \mathrm{g} / \mathrm{ml})$ in the presence of phosphate-buffered saline (PBS), goat polyclonal anti-MDA $(0.01,0.05,0.10$, or $0.15 \mathrm{mg} / \mathrm{ml}$ ), anti-apoB100 $(0.15 \mu \mathrm{g} / \mathrm{ml}$ ) (both antibodies from Academy Bio-Medical Co., USA) [17], preimmune goat serum, or recombinant soluble human FGF2 $(50 \mathrm{ng} / \mathrm{ml}$; Upstate Biotechnology, USA). DNA synthesis was quantified by measuring ${ }^{3} \mathrm{H}$-thymidine incorporation, as previously described [11,12]. ${ }^{3} \mathrm{H}$-thymidine was from Moravek Biochemicals, Inc. (USA) or DuPont NEN (USA). Cells were viewed under an inverted microscope and were counted by using a hemocytometer. The percentage of dead cells was determined according to trypan blue positivity. FGF2 concentrations were measured with an ELISA by using a Quantikine kit (R\&D Systems, USA), as previously described [11].

\section{Reverse transcription-polymerase chain reaction (RT-PCR)} RT-PCR was performed with total RNA and PCR primers for FGF2 or the gene encoding $\beta$-actin (used as an internal control), according to a previously described protocol [12]. The FGF2 primers were as follows: 5'-GGA-GTGTGT-GCT-AAC-CGT-TAC-CTG-GCT-ATG-3' (upstream) and 5'-TCA-GCT-CTT-AGC-AGA-CAT-TGG-AAGAAA-AAG-3' (downstream). $\beta$-actin primers were as follows: 5'-AAC-CGC-GAG-AAG-ATG-ACC-CAG-ATCATG-TTT-3' (upstream) and 5'-AGC-AGC-CGT-GGCCAT-CTC-TTG-CTC-GAA-GTC-3' (downstream). A fraction of each PCR product $(10 \mu \mathrm{l})$ was analyzed by using gel electrophoresis ( $2 \%$ agarose), and DNA bands were stained with ethidium bromide and visualized by using ultraviolet transillumination. Densitometric quantification was performed by using a PhosphorImager (Molecular Dynamics, USA).

\section{Inhibitors of signal transduction pathways}

To characterize the involvement of major signal transduction pathways, cells treated with or without antiMDA were also treated with $100 \mathrm{ng} / \mathrm{ml}$ pertussis toxin (PTX, a $\mathrm{Gi}$ protein inhibitor), $1 \mu \mathrm{g} / \mathrm{ml}$ Akt inhibitor (1 L6-hydroxymethyl-chiro-inositol-2-[R]-2-O-methyl-3O-octadecyl-sn-glycerocarbonate), or $0.4 \mu \mathrm{g} / \mathrm{ml} \mathrm{5-aza-}$ deoxycytidine (5-aza-dC; a methylation inhibitor) for 24 hours before exposure to oxLDL $(100 \mu \mathrm{g} / \mathrm{ml})$. All agents 
were purchased from Calbiochem (USA). Protocols for individual agents were determined on the basis of the maximal doses and durations tolerable by the cells; tolerability was defined as $<10 \%$ reduction in cell viability, as determined by using the MTT assay.

\section{Cell viability MTT assay}

HCAECs $\left(5 \times 10^{4}\right.$ cells/well $)$ were dispensed into 24-well plates and incubated for 24 hours with oxLDL $(100 \mu \mathrm{g} / \mathrm{ml})$ in the presence or absence of different treatments, and the index of EC viability was determined by using the colorimetric tetrazolium (MTT) assay. Absorbance was measured at a wavelength of $540 \mathrm{~nm}$ for viable cells by using a microplate reader (Thermo Electron Corporation, USA).

\section{DNA constructs, cell transfection, and luciferase reporter gene assay}

The reporter gene assay was performed by using a dualluciferase expression system (Promega, USA). Human FGF2 5'-flanking sequences [18] were amplified from human genomic DNA by using PCR, cloned into the pGL3-basic firefly luciferase reporter vector (Promega, USA), and sequenced. HCAECs were grown to $80 \%$ confluency in plastic 12-well plates and then transfected with $0.75 \mu \mathrm{g}$ of pGL3-basic or an equimolar amount of the different pGL3-FGF2 constructs by using Superfect ${ }^{\mathrm{m}}$ reagent, according to the manufacturer's instructions (Qiagen, USA). Cotransfection with $0.5 \mu \mathrm{g}$ of the Renilla luciferase expression vector phRL-TK was used as an internal control. Twenty-four hours after transfection, the cells were treated for 24 hours with $100 \mu \mathrm{g} / \mathrm{ml}$ oxLDL. Cell lysates were then prepared for luciferase assays by using Luciferin and a luminometer (Packard Instrument Company, Inc., USA). The promoter activity of the reporter construct was normalized to the promoter activity of phRL-TK and expressed as the fold increase relative to that in cells transfected with pGL3-basic.

\section{DNA sequence analysis and bisulfite genomic DNA sequencing}

The 5 '-flanking sequence of the human FGF2 gene was retrieved from GenBank and analyzed for CpG islands by using "CpG Island Searcher," available at the website http://www.cpgislands.com [19,20]. Transcription factor binding sites were analyzed by using the TRANSFAC database, available at http://www.gene-regulation.com/. To study DNA methylation, HCAECs that were cultured to $80 \%$ to $90 \%$ confluency were subjected to different treatments, followed by genomic DNA extraction performed according to standard procedures. With the use of the EpiTect bisulfite kit (Qiagen, USA), the reaction of genomic DNA $(2 \mu \mathrm{g})$ with bisulfite converted all unmethylated cytosine residues to uracil. Bisulfite-modified
DNA was amplified with FGF2-specific primers by using previously described cycling conditions [16].

\section{Statistical analysis}

The significance of the differences between group means was assessed by using a 2-way Student $t$ test for single comparisons and the Bonferroni test for multiple comparisons. Analysis of variance (ANOVA), followed by Scheffé's test for significance was used to compare values for concentration- and time-dependent responses. Probability values $<0.05$ were considered significant. Results are expressed as the mean \pm SEM.

\section{Results}

MDA mediates the effects of oxLDL on DNA synthesis, EC survival, and FGF2 expression

The exposure of HCAECs to oxLDL for 24 hours decreased DNA synthesis and cell viability in a concentrationdependent manner (Additional file 1: Figure S1). At a concentration of $100 \mu \mathrm{g} / \mathrm{ml}$, oxLDL significantly reduced DNA synthesis and cell viability $(P<0.05$ vs untreated control cells) without significantly increasing the percentage of dead cells (Additional file 1: Figure S1). At concentrations $>100 \mu \mathrm{g} / \mathrm{ml}$, oxLDL not only significantly decreased DNA synthesis and cell viability, but it also significantly increased the percentage of dead cells $(P<0.01$; Additional file 1: Figure S1). Therefore, we used an oxLDL concentration of $100 \mu \mathrm{g} / \mathrm{ml}$ for all subsequent experiments.

After HCAECs were treated with oxLDL $(100 \mu \mathrm{g} / \mathrm{ml})$ for 24 hours, DNA synthesis was decreased by $40 \%$ to $50 \%$ (Figure 1), a finding similar to those reported previously $[11,12]$. Treatment of HCAECs with FGF2 $(50 \mathrm{ng} / \mathrm{ml})$ alone had a potent mitogenic effect $(P<0.05)$, and cotreatment with FGF2 and oxLDL prevented the oxLDL-mediated inhibition of DNA synthesis. The inhibitory effect of oxLDL on DNA synthesis was also markedly attenuated in HCAECs cotreated with $0.15 \mu \mathrm{g} / \mathrm{ml}$ antiMDA, but not in those cotreated with anti-apoB100 (Figure 1). Treatment of HCAECs with oxLDL alone reduced the number of cells (Figure 2A) and significantly increased the percentage of trypan blue-positive cells (Figure $2 \mathrm{~B}, P<0.01$ vs control), whereas treatment with anti-MDA alone $(0.15 \mu \mathrm{g} / \mathrm{ml})$ had a negligible effect. Cotreatment of HCAECs with anti-MDA and oxLDL attenuated the cytotoxic effects of oxLDL (Figure 2A and B, $P<0.05$ vs oxLDL alone), whereas treatment with preimmune serum or anti-apoB100 had no protective effect (Figure 2A and B).

Because anti-MDA prevented the antiproliferative effect of oxLDL, we examined the effects of anti-MDA on FGF2 production by using ELISA. In HCAECs treated with oxLDL $(100 \mu \mathrm{g} / \mathrm{ml})$, the intracellular FGF2 concentration was decreased by $40 \%$ to $50 \%$ (Figure $3 \mathrm{~A}, P<0.05$ ). 


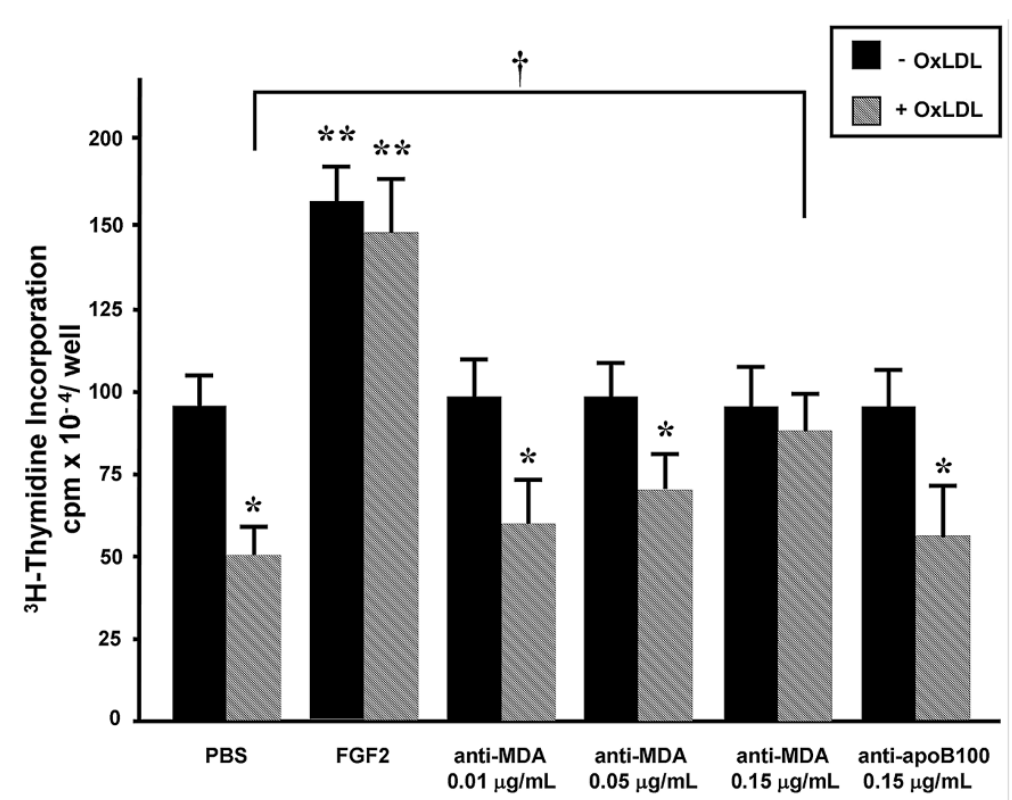

Figure 1 Role of the MDA epitope on the oxLDL-induced reduction of DNA synthesis, as determined by measuring ${ }^{3} \mathrm{H}$-thymidine incorporation. Cultured human coronary artery endothelial cells were incubated for 24 hours with or without oxLDL $(100 \mu \mathrm{g} / \mathrm{ml})$ in the presence or absence of anti-MDA $(0.01,0.05$, or $0.15 \mu \mathrm{g} / \mathrm{ml})$, anti-apoB100 $(0.15 \mu \mathrm{g} / \mathrm{ml})$, or FGF2 $(50 \mathrm{ng} / \mathrm{ml})$. Values shown are the mean \pm SEM $(n=3) .{ }^{*} P<0.05,{ }^{* *} P<0.01$ vs the oxLDL-untreated, PBS-treated control (first black column). ${ }^{\dagger} P<0.05$ between the indicated pair. MDA, malondialdehyde; oxLDL, oxidized low-density lipoprotein.

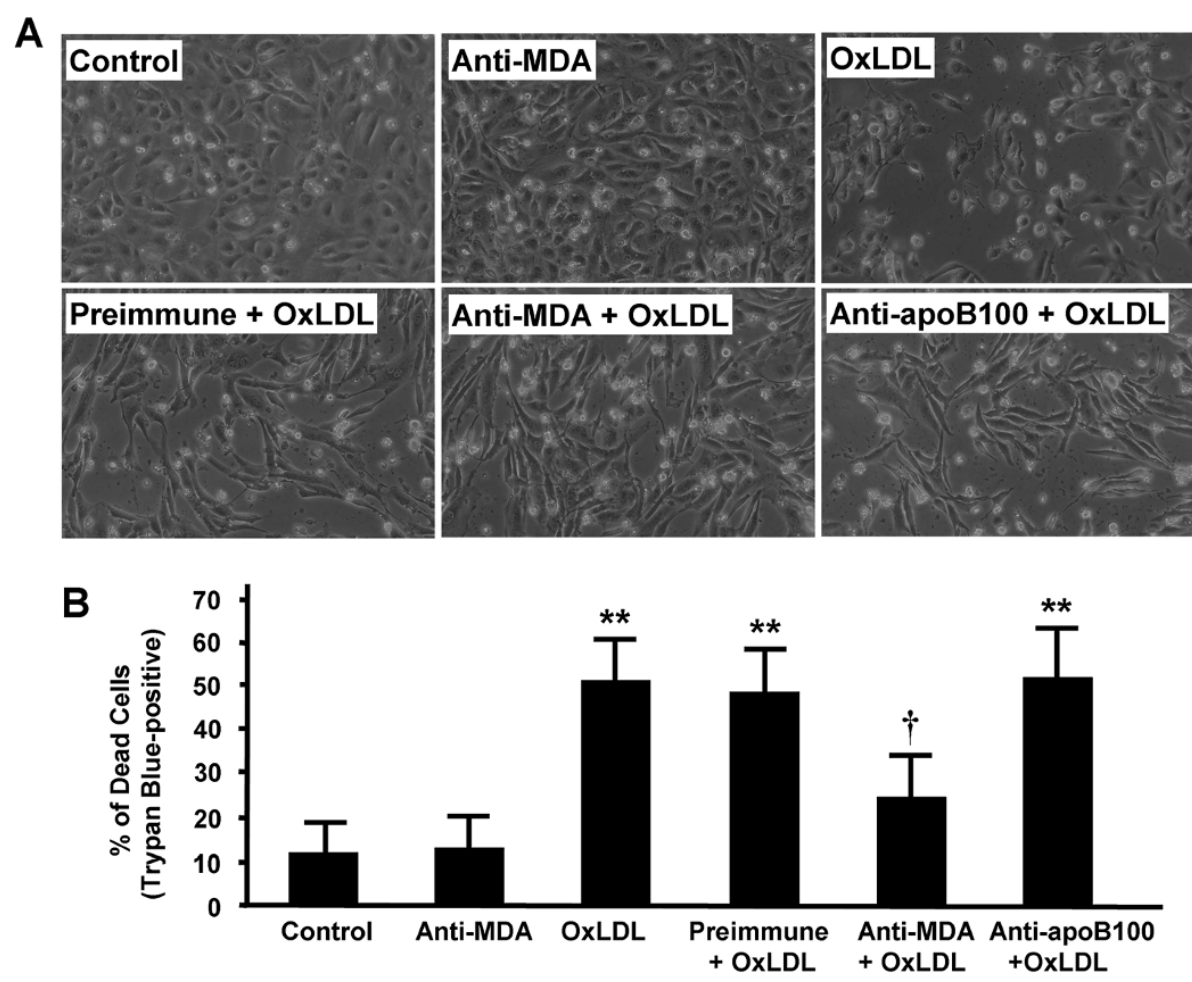

Figure 2 Role of the MDA epitope in oxLDL-induced human coronary artery endothelial cell (HCAEC) cytotoxicity. (A) HCAECs were incubated for 24 hours with or without oxLDL $(100 \mu \mathrm{g} / \mathrm{ml})$ in the presence or absence of anti-MDA $(0.15 \mu \mathrm{g} / \mathrm{ml})$, preimmune serum, or anti-apoB100 $(0.15 \mathrm{\mu g} / \mathrm{ml})$, as indicated; control cells were treated with PBS. Cells are shown under the view of an inverted microscope. (B) Percentage of trypan blue-positive cells expressed as the mean \pm SEM $(n=3) .{ }^{*} P<0.01$ vs control. ${ }^{\dagger} P<0.05$ vs oxLDL alone. MDA, malondialdehyde; oxLDL, oxidized low-density lipoprotein. 

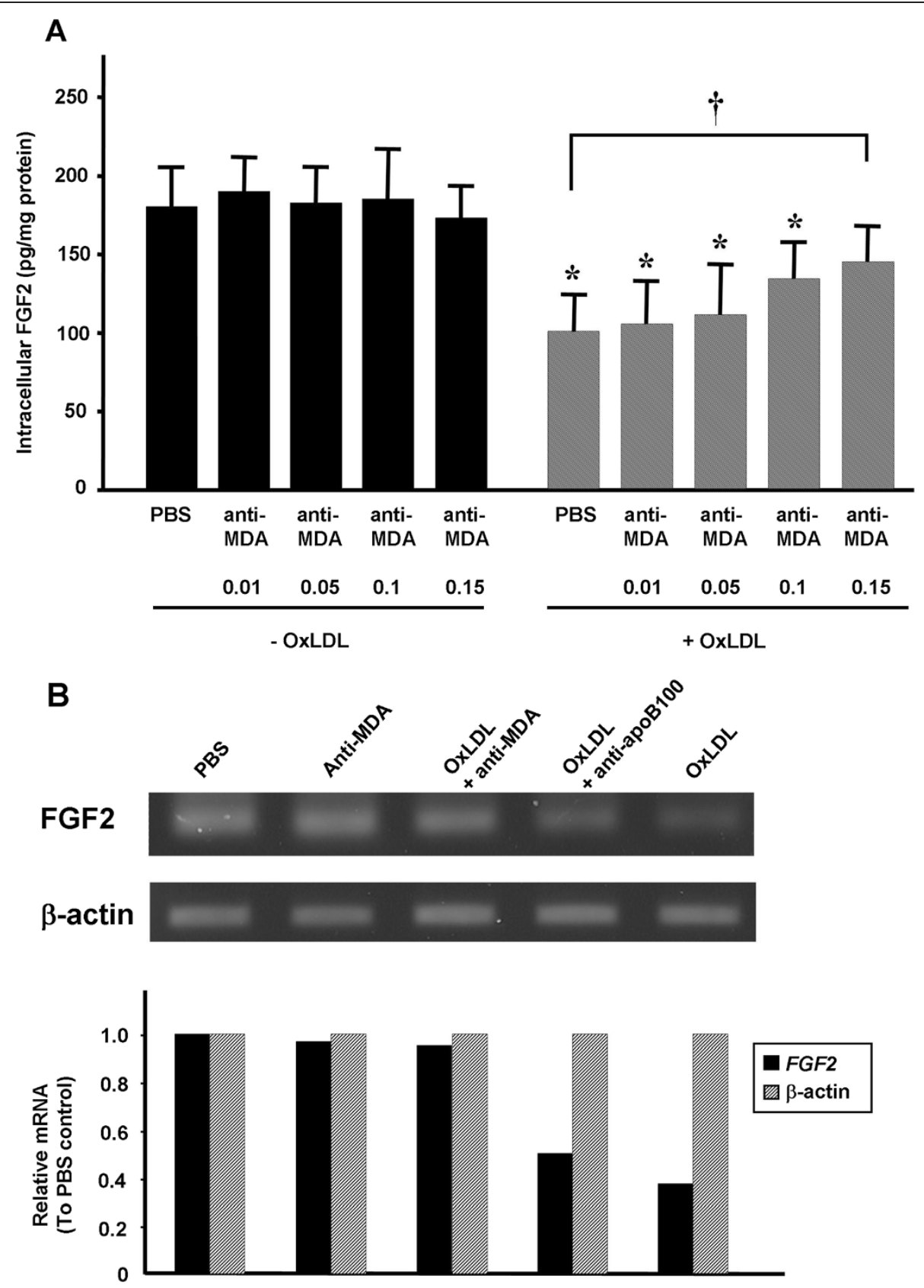

Figure 3 Effect of anti-MDA on oxLDL-regulated FGF2 expression. (A) Intracellular FGF2 protein concentrations in cultured human coronary artery endothelial cells (HCAECs) are shown, as determined with ELISA. Cells were incubated for 24 hours with or without oxLDL (100 $\mu \mathrm{g} / \mathrm{ml})$ in the presence or absence of anti-MDA $(0.01,0.05,0.1$, or $0.15 \mu \mathrm{g} / \mathrm{ml})$. Values shown are the mean $\pm \operatorname{SEM}(n=3)$. ${ }^{*} P<0.05$, ${ }^{* *} P<0.01$ vs the oxLDL-untreated PBS control. ${ }^{\dagger} P<0.05$ vs the oxLDL-treated PBS control. (B) FGF2 mRNA levels in HCAECs relative to those in the PBS-treated control, as determined by using RT-PCR. HCAECs were incubated for 24 hours with the indicated reagents, and total RNA was subjected to RT-PCR analysis by using specific primers for FGF2 and the gene encoding $\beta$-actin (internal control). The upper panel shows a gel representative of 3 separate experiments, and the lower panel shows the densitometric quantification. MDA, malondialdehyde; OxLDL, oxidized low-density lipoprotein.

In oxLDL-untreated HCAECs, FGF2 levels were similar between cells treated with PBS and those treated with anti-MDA (0.01-0.15 $\mu \mathrm{g} / \mathrm{ml})$; however, in oxLDL-treated cells, cotreatment with anti-MDA attenuated the inhibitory effect of oxLDL on FGF2 expression in a dose- dependent manner (Figure 3A, $P<0.05$ vs $\mathrm{PBS}+$ oxLDL). In addition, RT-PCR analysis showed that oxLDL reduced FGF2 mRNA levels by $50 \%$ when compared to the PBS control-an effect that was prevented by anti-MDA ( 0.15 $\mu \mathrm{g} / \mathrm{ml})$ but not anti-apoB100 $(0.15 \mu \mathrm{g} / \mathrm{ml})$ (Figure 3B). 
The effects of MDA are mediated through Akt and involve DNA methylation

To investigate the signal transduction pathways of MDA in oxLDL-treated HCAECs, we examined the effects of pharmacologic inhibitors on cell viability (Figure 4). Compared with cells treated with PBS only (first black column), cells also treated with oxLDL $(100 \mu \mathrm{g} / \mathrm{ml})$ for 24 hours showed a $40 \%$ decrease in cell viability. This inhibitory effect of oxLDL was remarkably blocked in cells cotreated with either PTX, a G protein inhibitor, or with 5-aza-dC, a methylation inhibitor. When HCAECs were cotreated with both oxLDL and anti-MDA, the oxLDLinduced reduction in cell viability was blocked, which was unaffected by the addition of PTX or 5-aza-dC. However, the addition of Akt inhibitor significantly attenuated the effect of anti-MDA (last column). These results indicate that the Akt signaling pathway and DNA methylation are involved in mediating cell proliferation in anti-MDA/oxLDL-treated HCAECs.

\section{The FGF2 promoter is regulated by oxLDL and MDA}

To determine whether the reduced FGF2 expression observed in oxLDL-treated cells resulted from decreased FGF2 gene transcription, we evaluated $F G F 2$ promoter activity in the presence or absence of oxLDL $(100 \mu \mathrm{g} / \mathrm{ml})$ by using a luciferase reporter gene assay. Human FGF2 genomic sequences containing the FGF2 promoter were generated by using PCR and were cloned into the firefly luciferase vector, pGL3 (Figure 5A). In the absence of oxLDL, the $-126 /+43$ and $-126 /+179$ constructs containing the FGF2 promoter induced FGF2 gene expression 120 -fold more than did the pGL3-basic vector (Figure 5B). Deletion of the FGF2 promoter from position -126 to +24 resulted in an $80 \%$ reduction in FGF2 gene expression, confirming the removal of a basal promoter in this region. The addition of oxLDL $(100 \mu \mathrm{g} / \mathrm{ml})$ reduced FGF2 expression in cells transfected with constructs $-126 /+43$ and $126 /+179$ by $30 \%$ to $40 \%(P<0.05)$. However, the presence of anti-MDA prevented the oxLDL-induced repression of FGF2 promoter activity. Furthermore, attenuation of the oxLDL-induced repression of FGF2 promoter activity by anti-MDA was partially prevented by Akt inhibitor (Additional file 1: Figure S2), suggesting the involvement of Akt in the regulation of FGF2 expression by MDA and oxLDL. Our results suggest that FGF2 transcription in HCAECs can be repressed by oxLDL and that this effect is mediated through the MDA epitope. The preservation of FGF2 promoter activity by anti-MDA is in agreement with our RT-PCR results (Figure 3B).

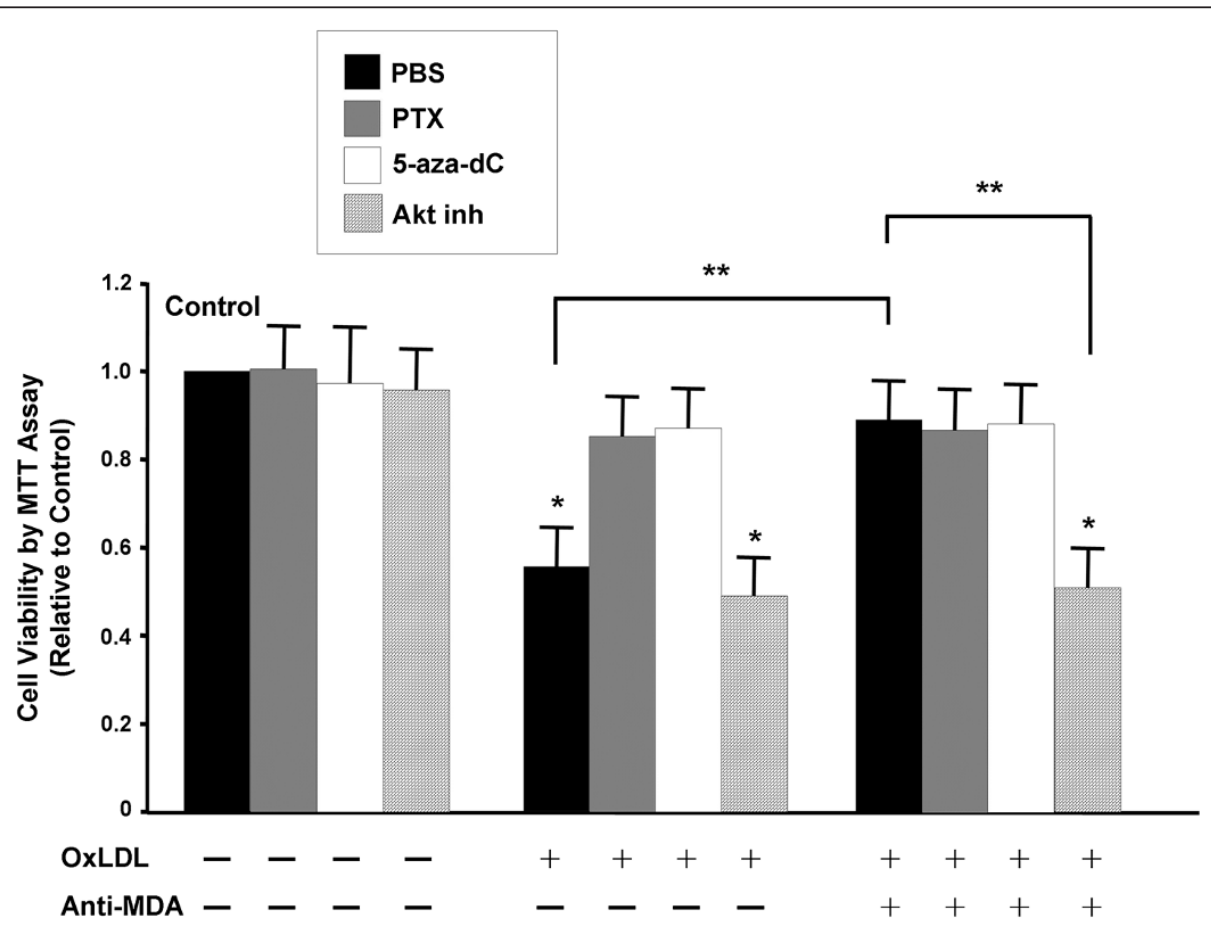

Figure 4 Effects of signal transduction inhibitors on the oxLDL-induced reduction of cell viability, as determined by using the MTT assay in cultured human coronary artery endothelial cells (HCAECs). HCAECs were incubated for 24 hours with signaling pathway modifiers in the presence or absence of oxLDL $(100 \mu \mathrm{g} / \mathrm{ml})$ and anti-MDA $(0.15 \mu \mathrm{g} / \mathrm{ml})$, as indicated. The cell viability after each treatment was normalized to that of the PBS control (first black column). Values shown are mean \pm SEM $(n=3) .{ }^{*} P<0.05$ vs control (first black column); ${ }^{*} P<0.05$ between the indicated pair. 5-aza-dC, 5-aza-deoxycytidine; Akt inh, Akt inhibitor; MDA, malondialdehyde; oxLDL, oxidized low-density lipoprotein; PTX, pertussis toxin. 


\section{A}
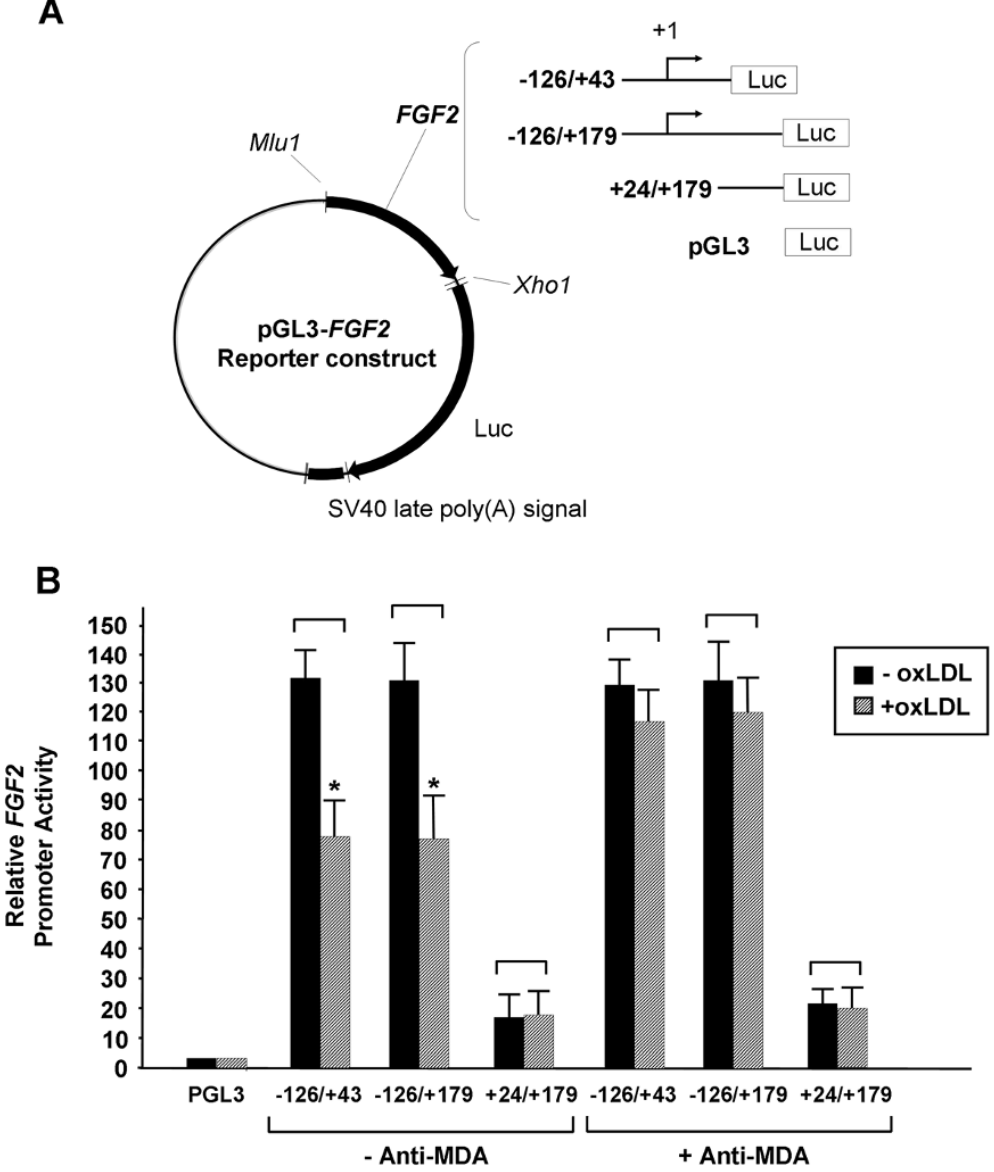

Figure 5 Effects of anti-MDA and oxLDL on the transcriptional regulation of FGF2 in cultured human coronary artery endothelial cells (HCAECs). (A) A diagram showing the different FGF2 reporter gene constructs used. Different lengths of human FGF2 5'-flanking sequences were cloned into the pGL3-basic luciferase reporter vector. +1 indicates the transcription start site. (B) FGF2 promoter activity is shown, as determined by using a luciferase reporter gene assay. HCAECs were cotransfected with the indicated constructs and phRL-TK (internal control) and were incubated for $24 \mathrm{~h}$ with or without oxLDL $(100 \mu \mathrm{g} / \mathrm{ml})$ in the presence or absence of anti-MDA $(0.15 \mu \mathrm{g} / \mathrm{ml})$. Luciferase activities are expressed relative to those in cells transfected with pGL3-basic. Values shown are the mean \pm SEM $(n=3-5)$. * $P<0.05$ vs corresponding oxLDL-untreated controls. Luc, luciferase reporter gene; MDA, malondialdehyde; oxLDL, oxidized low-density lipoprotein.

\section{OxLDL and MDA regulate the FGF2 promoter via methylation of a $\mathrm{CpG}$ island}

Genomic sequence analysis of human FGF2 confirmed the absence of a TATA sequence and revealed the presence of multiple GC boxes (GGGCGG or CCGCCC) (Figure 6). Using the "CpG Island Searcher" database to search for CpG dinucleotides, we identified a 1877-bp CpG island that starts at -532 in the $5^{\prime}$-flanking region of FGF2 and extends through exon 1 into the first intron. This portion of the human FGF2 gene contains the oxLDL-responsive promoter that we previously showed can be regulated by homocysteine [16]. A computer scan of the TRANSFAC database disclosed several possible binding sites for transcription factors, including 2 GC boxes in the oxLDL/MDA-responsive promoter (Figure 6).

Because CpG methylation is a key factor for FGF2 gene expression, we investigated whether MDA mediates the oxLDL-induced suppression of FGF2 expression through this epigenetic modification. The methylation status of $\mathrm{CpG}$ dinucleotides in the FGF2 promoter was characterized by performing bisulfite genomic DNA sequencing in HCAECs (Figure 7). Twenty CpG dinucleotides (numbered 1-20 in Figure 7) in the FGF2 promoter region were analyzed by using 2 pairs of primers (CpG primer $1 \mathrm{~S} / 1 \mathrm{AS}$; CpG primer $2 \mathrm{~S} / 2 \mathrm{AS}$ ) designed to amplify the $F G F 2$ promoter region (Figure 7A). In PBS-treated control cells, none of the 20 cytosine residues was methylated (Figure 7B). In contrast, all 20 cytosine residues were methylated in cells treated with oxLDL $(100 \mu \mathrm{g} / \mathrm{ml})$. Furthermore, when anti-MDA was added to oxLDL-treated HCAECs, methylation of the cytosine residues was markedly reduced: only 4 of the 20 remained methylated (Figure 7B).

To determine whether oxLDL induced the upregulation of DNA methyltransferases in HCAECs, we examined the 


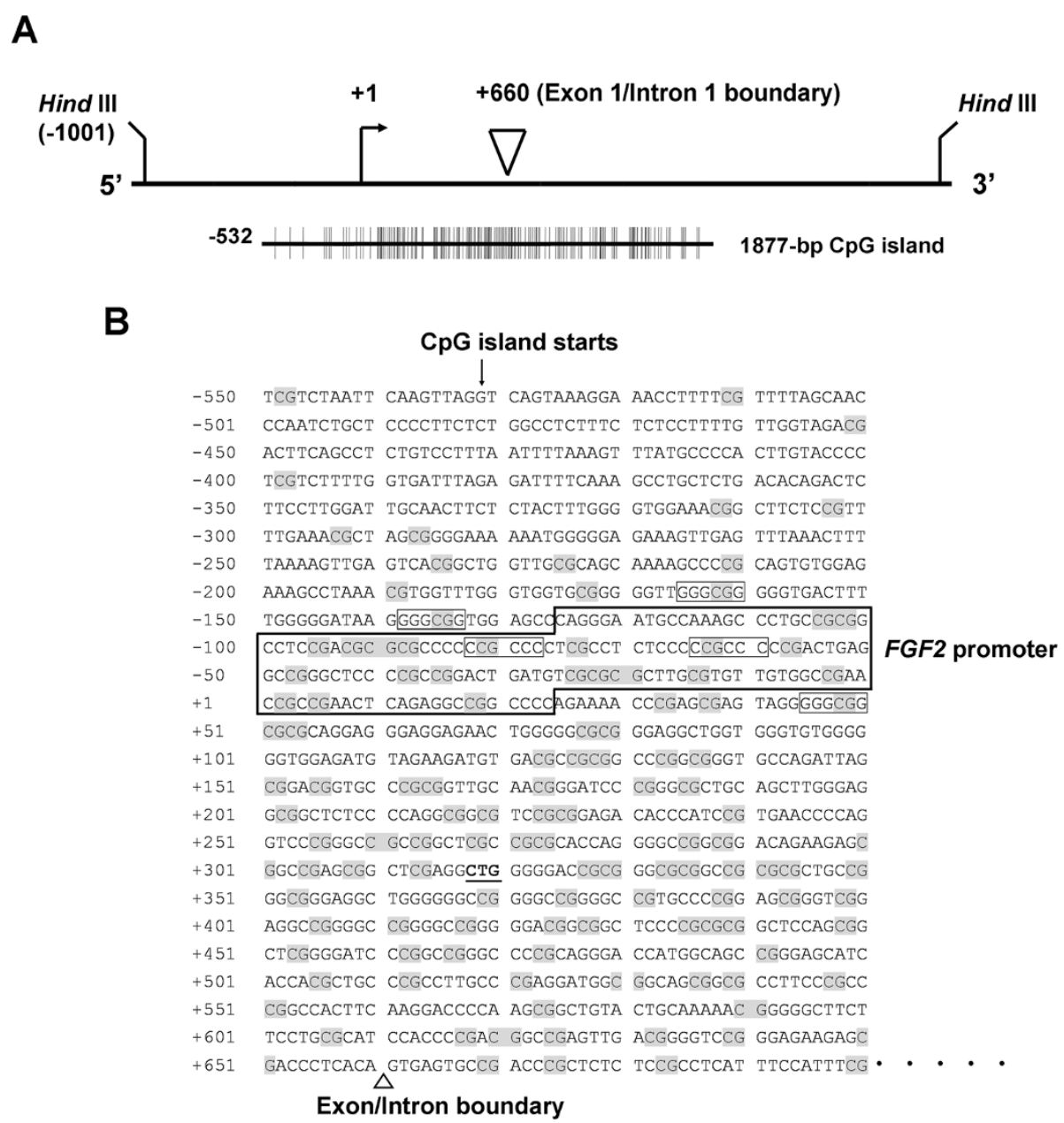

Figure 6 The human FGF2 gene promoter. (A) Schematic representation of the CpG island promoter of human FGF2. The numbers are the nucleotide positions relative to the +1 transcription start site. Each CpG dinucleotide is shown by a vertical line. (B) Part of the genomic DNA sequence of FGF2 is shown, featuring the FGF2 promoter, GC boxes (outlined), and CpG dinucleotides (shaded). The CpG island start site (downward arrow in B), the exon-intron boundary (triangle in $\mathbf{B}$ ), and the translation start codon (CTG in $\mathbf{B}$ ) are indicated.

mRNA levels of DNA methyltransferase (DNMT)1, $D N M T 3 A$, and DNMT3B by using real-time PCR. We observed a modest oxLDL-induced increase in the levels of DNMT1 and DNMT3B mRNA, which was attenuated by anti-MDA (Additional file 1: Figure S3). These data indicate that oxLDL represses FGF2 transcription in ECs by promoting the methylation of CpG dinucleotides in the FGF2 promoter-an action that is mediated through the oxidative MDA epitope of oxLDL.

\section{Discussion}

The aim of this study was to elucidate the mechanisms underlying the regulation of cell proliferation and FGF2 expression in ECs exposed to oxLDL. We found that oxLDL-induced EC damage can be prevented by antiMDA, which blocks the oxLDL-induced reduction of intracellular FGF2 levels through an Akt-dependent pathway. Furthermore, the effect of MDA was mediated through the transcriptional repression of the FGF2 promoter, which involved CpG methylation. Thus, we showed that MDA exerts its deleterious effects on ECs through an FGF2-dependent pathway, which may be the mechanism underlying the atherogenic nature of oxLDL. The schematic in Figure 8 outlines the signaling pathway through which MDA mediates endothelial cytotoxicity in the presence of oxLDL.

FGF2, a potent angiogenic factor involved in all aspects of angiogenesis (eg, EC proliferation and migration and vascular differentiation), is an indicator of EC survival $[21,22]$. Previously, we showed that both oxLDL and electronegative LDL downregulate endothelial FGF2 expression by inhibiting $\mathrm{Gi}$, a heterotrimeric $\mathrm{G}$ protein $[11,12]$. In the current study, PTX, a Gi inhibitor, attenuated oxLDL-mediated effects on FGF2 expression, further supporting the important role of Gi protein in the oxLDL signaling pathway. Because circulating oxLDL 
A

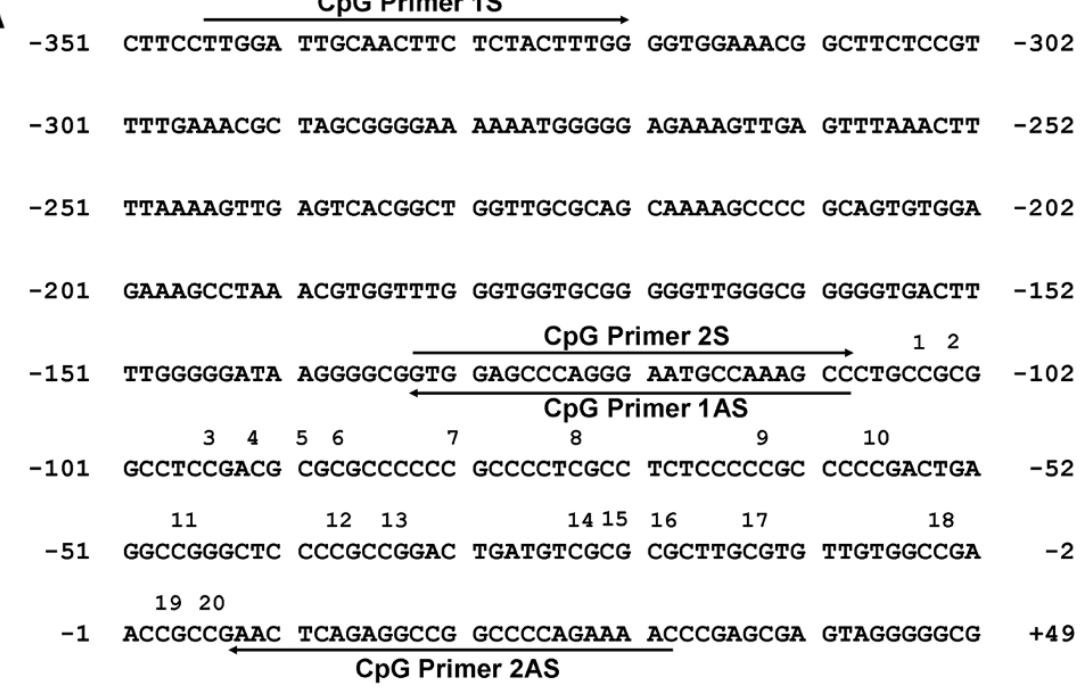

B

\begin{tabular}{|c|c|c|c|c|}
\hline Control & $\begin{array}{lllll}12 & 3456 & 7 & 8 \\
ل & ل & ل & & \\
\end{array}$ & $\begin{array}{llll}9 & 10 & 11 & 12 \\
ل & & & \\
\end{array}$ & $\begin{array}{c}1416 \\
-ل \\
\end{array}$ & $\begin{array}{cc}17 & 181920 \\
ل & ل \perp \\
\end{array}$ \\
\hline OxLDL+Anti-MDA & 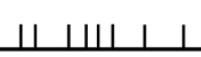 & $\begin{array}{llll} & \perp & & \end{array}$ & Ш & 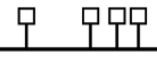 \\
\hline OxLDL & 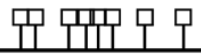 & 무무 & 界 & 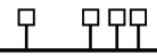 \\
\hline
\end{tabular}

Figure 7 FGF2 promoter analysis. (A) The CpG island sequence in the promoter region of human FGF2 is shown. The human FGF2 promoter contains $20 \mathrm{CpG}$ sites, numbered 1-20. The primers used for DNA methylation sequencing are shown. (B) An illustration showing the methylation status of the CpG dinucleotides in human coronary artery endothelial cells treated for 24 hours with oxLDL $(100 \mu \mathrm{g} / \mathrm{ml})$ in the presence or absence of anti-MDA $(0.15 \mu \mathrm{g} / \mathrm{ml})$. Unmethylated cytosines are indicated by stalks. Methylated cytosines are indicated by stalks with square heads. MDA, malondialdehyde; oxLDL, oxidized low-density lipoprotein.

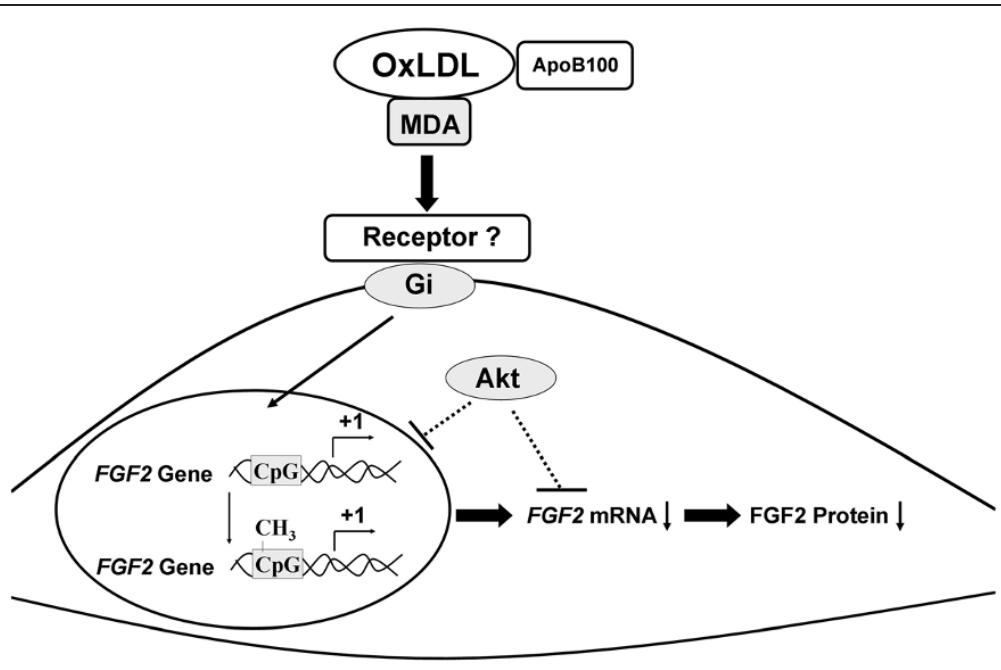

\section{Endothelial Cells}

Figure 8 A schematic illustration of FGF2 regulation by the MDA epitope of oxLDL in human coronary artery endothelial cells. The transcription start site of the FGF2 gene is indicated as +1 . Methylation of the cytosine residues of $\mathrm{CpG}$ dinucleotides is indicated by $-\mathrm{CH}_{3}$. Arrows indicate stimulation or direction of transportation. Lines with an end bar indicate inhibition. 
and MDA-LDL levels are greatly increased in individuals who have coronary events [5-8,23], FGF2 downregulation by oxLDL may be an important mechanism underlying the impaired angiogenic response in atherosclerosis. In addition, involvement of the MDA epitope in oxLDLinduced angiostatic effects supports the use of MDA as a biomarker in cardiovascular diseases [5-8].

Although oxLDL is known to modulate the expression of many genes, its effect on FGF2 promoter activity has not been previously reported. We found that the oxLDLinduced downregulation of FGF2 expression is caused by transcriptional repression of the FGF2 gene promoter and that this repression could be effectively prevented by 5 -aza-dC. The 5'-flanking regions of the FGF2 promoter are responsible for the basal transcription of the FGF2 gene, the subcellular distribution of FGF2 protein in adrenal medullary cells $[18,24]$, and the cell density-dependent regulation of FGF2 levels in human astrocytes [25]. In the current study, we identified a 5 '-flanking region in the FGF2 promoter from -126 to +24 (which conforms to the published mapping of the FGF2 gene promoter) that functions as an oxLDL-responsive element. The FGF2 promoter is located in a CpG island, which is defined as a region of DNA larger than $500 \mathrm{bp}$ that has a moving average $\%(\mathrm{G}+\mathrm{C})$ greater than 55 and an observed/expected $\mathrm{CpG}$ dinucleotide ratio greater than $0.65[19,20]$. The CpG island of the human FGF2 gene contains multiple GC boxes (GGGCGG or CCGCCC) and a basal promoter, which responded to oxLDL in our transient transfection system. We found that the CpG-rich FGF2 promoter was heavily methylated by oxLDL, resulting in the subsequent suppression of $F G F 2$ transcription.

Previously, we have shown that L5, the most electronegative subfraction of LDL obtained by using anionexchange chromatography, downregulates endothelial FGF2 expression at the transcriptional level by inhibiting Akt phosphorylation [26]. Furthermore, it has been shown that the L5-induced reduction in FGF2 expression can be attenuated by aspirin through a signaling pathway that requires Akt [27]. In the present study, the ability of Akt inhibitor to counteract the effects of antiMDA in HCAECs further supports the important role of Akt in the oxLDL-FGF2 signaling pathway. Moreover, the involvement of Akt in the regulation of the FGF2 promoter by oxLDL also implies a complex interplay between cellular survival and different signaling pathways in the response to atherogenic oxLDL.

Epigenetics is a phenomenon characterized by heritable changes in the phenotypic expression of genetic information that occurs without changes in DNA sequence. Emerging data suggest that epigenetic modifications affect the development of cardiovascular diseases, such as human heart failure and atherosclerosis [28,29]. DNA methylation, an epigenetic modification that occurs throughout the genome, is the addition of a methyl group to the cytosine residues preceding a guanosine (ie, CpG dinucleotides). This modification has been studied extensively and represents a well-understood epigenetic mechanism. Abnormal methylation of $\mathrm{CpG}$ islands in the promoter region of genes can be caused by exogenous stimuli such as smoking and oxidative stress, often leading to the silencing of genetic information and subsequent alterations in biologic function [30].

OxLDL has been shown to alter DNA promoter methylation in cultured ECs. In human umbilical vein ECs (HUVECs), oxLDL-induced apoptosis has been associated with upregulation of the proapoptotic genes $L O X-1, A N X A 5, B A X$, and CASP3 and inhibition of the anti-apoptotic genes $B C L 2$ and $C I A P-1$. Interestingly, the upregulation of these apoptosis-related genes was consistently accompanied by reciprocal changes in the methylation of the respective promoter regions [31]. However, promoter methylation induced by oxLDL is not always accompanied by reciprocal changes in gene expression. At different concentrations, oxLDL can differentially regulate the methylation status of the estrogen receptor alpha gene [32]. In addition, oxLDL can upregulate microRNA-29b, leading to epigenetic modifications of the matrix metalloproteinase (MMP)-2/ MMP-9 genes [33]. Our discovery that the oxLDLinduced downregulation of FGF2 expression can be attenuated by 5 -aza-dC, a well-known demethylating reagent [34], also supports that oxLDL promotes hypermethylation of the FGF2 promoter, as illustrated in Figure 8.

Our study shows that oxLDL can specifically downregulate FGF2 expression in arterial ECs, revealing a novel, angiostatic function for oxLDL. Because oxLDL and homocysteine are both risk factors for atherosclerosis, the possibility remains that they synergistically promote EC cytotoxicity through a shared pathway related to FGF2 [16]. The notion that there is close interplay between homocysteine and oxLDL has been suggested by previous findings showing that homocysteine enhances the oxidation of human LDL in HUVECs and facilitates the subsequent uptake of oxLDL by macrophages [35]. Moreover, homocysteine can upregulate the expression of lectin-like oxLDL receptor-1 (LOX-1) in endothelial and mononuclear cells and increase the toxicity of oxLDL [36]. Collectively, our results support the idea that crosstalk occurs between the cardiovascular risk factors oxLDL and homocysteine and that the upregulation or reintroduction of FGF2 may counteract their pathologic effects in ECs.

\section{Conclusions}

We have shown that oxLDL-induced impairment of EC integrity and survival is mediated by the MDA epitope 
and involves FGF2 promoter methylation and the downregulation of intracellular FGF2. This signaling pathway through which MDA mediates endothelial cytotoxicity in the presence of oxLDL is outlined in Figure 8. Because high circulating levels of oxLDL and MDA-LDL are strongly associated with atherosclerotic diseases $[37,38]$, we propose that the maintenance of FGF2 expression may provide protection of the endothelium in patients with these diseases. Furthermore, DNA demethylation may have therapeutic applications for protecting ECs against oxLDL-induced cell death and for preventing plaque instability.

\section{Additional files}

Additional file 1: Figure S1. Effects of oxLDL on DNA synthesis, cell viability, and cell death in cultured HCAECs. Cells were treated with increasing concentrations of oxLDL for 24 hours, and DNA synthesis (•), cell viability $(\square)$, and cell death $(\Delta)$ were assessed. Values are expressed as the mean \pm SEM $(n=3) .{ }^{*} P<0.05,{ }^{* *} P<0.01$ vs corresponding untreated controls. Figure S2. Involvement of DNA methylation and Akt signaling pathway in FGF2 promoter regulation. Human coronary artery endothelia cells (HCAECs) were cotransfected with the reporter constructs $-126 /+179$ or -126/+179 and phRL-TK (internal control), followed by incubation with L5 $(100 \mu \mathrm{g} / \mathrm{ml})$, 5-aza-dC (5-aza-deoxycytidine, $0.4 \mu \mathrm{g} / \mathrm{ml})$, or Akt inhibitor $(1 \mu \mathrm{g} / \mathrm{ml})$ in the presence or absence of anti-MDA $(0.15 \mu \mathrm{g} / \mathrm{ml})$. Luciferase activity was expressed as a fold-increase of that for pGL3-basic. Values are expressed as the mean \pm SEM and are representative of 3 to 5 independent experiments. ${ }^{*} P<0.05$ between the indicated pair. PBS, phosphate-buffered saline. Figure S3. Effects of oxLDL on DNA methyltransferase (DNMT) mRNA expression. Human coronary artery endothelial cells (HCAECs) were incubated with phosphate-buffered saline (PBS), native LDL $(100 \mu \mathrm{g} / \mathrm{ml})$, anti-MDA $(0.15 \mu \mathrm{g} / \mathrm{ml})$, oxLDL $(100 \mu \mathrm{g} / \mathrm{ml})$, or oxLDL+anti-MDA as indicated for 24 hours, and total RNA was subjected to real-time polymerase chain reaction analysis with specific primers for DNMT1, DNMT3A, DNMT3B, and $\beta$-actin. The values in the graph are expressed relative to that of the PBS control after normalization to $\beta$-actin and are presented as the mean \pm SEM representative of 3 to 5 independent experiments. ${ }^{*} P<0.05$ vs PBS-treated control; ${ }^{* *} P<0.05$ between the indicated pair (oxLDL+anti-MDA and oxLDL alone). Table S1. Primer sequences used for real-time polymerase chain reaction (PCR), reporter gene constructs, and CPG methylation studies.

\section{Abbreviations}

5-aza-dC: 5-aza-deoxycytidine; ApoB100: Apolipoprotein B100; HCAEC: Human coronary artery endothelial cell; EC: Endothelial cell; FGF2: Fibroblast growth factor 2; MDA: Malondialdehyde; oxLDL: Oxidized low-density lipoprotein; PTX: Pertussis toxin.

\section{Competing interests}

The authors declare that they have no competing interests.

\section{Authors' contributions}

PYC and SCL conceived and designed the experiments. TCY and YJC performed the experiments. PYC, SFC, and CHC analyzed the data. TCY, PYC LSC and CHC wrote the paper. All authors have read and approved the final manuscript.

\section{Acknowledgments}

This study was supported by grants NSC 91-2320-B-002-185, 93-2314-B-002-125, 94-2320-B-002-121, 95-2320-B-002-116, 98-2628-B-002-088, 97-2320-B-002-057-MY3, 100-2314-B-039-040-MY3, and 101-2320-B-002-026 from the National Science Council, Taipei, Taiwan (Drs. Chang, Lu, and Chen); grants NTUH 92A14, 93A02, and $95 \mathrm{~S} 342$ from the National Taiwan University Hospital, Taipei, Taiwan (Dr. Chang); grant DOH102-TD-B-111-004 from the Taiwan Department of Health, Clinical Trial, and Research Center of Excellence (Dr. Chen); and research grant 1-04-RA-13 from the American Diabetes Association (Dr. Chen).
The authors thank Heather Leibrecht, MS, and Nicole Stancel, PhD, ELS, of the Texas Heart Institute, for editorial assistance in the preparation of this manuscript.

\section{Author details}

'Department of Biochemistry and Molecular Biology, National Taiwan University College of Medicine, Taipei, Taiwan. ${ }^{2}$ Graduate Institute of Medical Sciences, College of Medicine, Taipei Medical University, Taipei, Taiwan. ${ }^{3}$ Department of Medicine, Vascular and Medicinal Research, Texas Heart Institute, Houston, TX, USA. ${ }^{4}$ L5 Research Center, China Medical University Hospital, Taichung, Taiwan. ${ }^{5}$ Center for Lipid Biosciences and Department of Medicine, Kaohsiung Medical University, Kaohsiung, Taiwan. ${ }^{6}$ Cardiovascular Center and Division of Cardiology, Department of Internal Medicine, National Taiwan University Hospital and College of Medicine, No. 7 . Chung-Shan South Road, Taipei 100, Taiwan.

Received: 1 September 2013 Accepted: 29 January 2014 Published: 3 February 2014

\section{References}

1. Ehara S, Ueda M, Naruko T, Haze K, Itoh A, Otsuka M, Komatsu R, Matsuo T, Itabe H, Takano T, et al: Elevated levels of oxidized low density lipoprotein show a positive relationship with the severity of acute coronary syndromes. Circulation 2001, 103:1955-1960.

2. Lahoute $\mathrm{C}$, Herbin $\mathrm{O}$, Mallat $\mathrm{Z}$, Tedgui A: Adaptive immunity in atherosclerosis: mechanisms and future therapeutic targets. Nat Rev Cardiol 2011, 8:348-358.

3. Navab M, Ananthramaiah GM, Reddy ST, Van Lenten BJ, Ansell BJ, Fonarow GC, Vahabzadeh K, Hama S, Hough G, Kamranpour N, et al: The oxidation hypothesis of atherogenesis: the role of oxidized phospholipids and HDL. J Lipid Res 2004, 45:993-1007.

4. Shaw PX, Horkko S, Tsimikas S, Chang MK, Palinski W, Silverman GJ, Chen PP Witztum JL: Human-derived anti-oxidized LDL autoantibody blocks uptake of oxidized LDL by macrophages and localizes to atherosclerotic lesions in vivo. Arterioscler Thromb Vasc Biol 2001, 21:1333-1339.

5. Grune T, Berger MM: Markers of oxidative stress in ICU clinical settings: present and future. Curr Opin Clin Nutr Metab Care 2007, 10:712-717.

6. Duryee MJ, Klassen LW, Schaffert CS, Tuma DJ, Hunter CD, Garvin RP Anderson DR, Thiele GM: Malondialdehyde-acetaldehyde adduct is the dominant epitope after MDA modification of proteins in atherosclerosis. Free Radic Biol Med 2010, 49:1480-1486.

7. Tsimikas S, Miyanohara A, Hartvigsen K, Merki E, Shaw PX, Chou MY, Pattison J, Torzewski M, Sollors J, Friedmann T, et al: Human oxidation-specific antibodies reduce foam cell formation and atherosclerosis progression. J Am Coll Cardiol 2011, 58:1715-1727.

8. Lopes-Virella MF, Hunt KJ, Baker NL, Virella G, Moritz T: The levels of MDA-LDL in circulating immune complexes predict myocardial infarction in the VADT study. Atherosclerosis 2012, 224:526-531.

9. Liao JK, Shin WS, Lee WY, Clark SL: Oxidized low-density lipoprotein decreases the expression of endothelial nitric oxide synthase. J Biol Chem 1995, 270:319-324.

10. Liao JK, Clark SL: Regulation of G-protein alpha i2 subunit expression by oxidized low-density lipoprotein. J Clin Invest 1995, 95:1457-1463.

11. Chang PY, Luo S, Jiang T, Lee YT, Lu SC, Henry PD, Chen CH: Oxidized low-density lipoprotein downregulates endothelial basic fibroblast growth factor through a pertussis toxin-sensitive G-protein pathway: mediator role of platelet-activating factor-like phospholipids. Circulation 2001, 104:588-593.

12. Chen CH, Jiang W, Via DP, Luo S, Li TR, Lee YT, Henry PD: Oxidized low-density lipoproteins inhibit endothelial cell proliferation by suppressing basic fibroblast growth factor expression. Circulation 2000, 101:171-177.

13. Chen CH, Cartwright J Jr, Li Z, Lou S, Nguyen HH, Gotto AM Jr, Henry PD: Inhibitory effects of hypercholesterolemia and ox-LDL on angiogenesis-like endothelial growth in rabbit aortic explants. Essential role of basic fibroblast growth factor. Arterioscler Thromb Vasc Biol 1997, 17:1303-1312.

14. Seghezzi G, Patel S, Ren CJ, Gualandris A, Pintucci G, Robbins ES, Shapiro RL, Galloway AC, Rifkin DB, Mignatti P: Fibroblast growth factor-2 (FGF-2) induces vascular endothelial growth factor (VEGF) expression in the endothelial cells of forming capillaries: an autocrine mechanism contributing to angiogenesis. J Cell Biol 1998, 141:1659-1673. 
15. Tiefenbacher $C P$, Chilian WM: Basic fibroblast growth factor and heparin influence coronary arteriolar tone by causing endothelium-dependent dilation. Cardiovasc Res 1997, 34:411-417.

16. Chang PY, Lu SC, Lee CM, Chen YJ, Dugan TA, Huang WH, Chang SF, Liao WS, Chen CH, Lee YT: Homocysteine inhibits arterial endothelial cell growth through transcriptional downregulation of fibroblast growth factor-2 involving G protein and DNA methylation. Circ Res 2008, 102:933-941.

17. Yang CY, Raya IL, Chen HH, Chen CH, Abe Y, Pownall HJ, Taylor AA, Smith $\mathrm{CV}$ : Isolation, characterization, and functional assessment of oxidatively modified subfractions of circulating low-density lipoproteins. Arterioscler Thromb Vasc Biol 2003, 23:1083-1090.

18. Shibata F, Baird A, Florkiewicz RZ: Functional characterization of the human basic fibroblast growth factor gene promoter. Growth Factors 1991, 4:277-287.

19. Bird AP: CpG-rich islands and the function of DNA methylation. Nature 1986, 321:209-213.

20. Takai $\mathrm{D}$, Jones PA: Comprehensive analysis of $\mathrm{CpG}$ islands in human chromosomes 21 and 22. Proc Natl Acad Sci U S A 2002, 99:3740-3745.

21. Chang PY, Lu SC, Su TC, Chou SF, Huang WH, Morrisett JD, Chen CH, Liau $C S$, Lee $Y T$ : Lipoprotein- $X$ reduces $L D L$ atherogenicity in primary biliary cirrhosis by preventing LDL oxidation. J Lipid Res 2004, 45:2116-2122.

22. Klein S, Roghani M, Rifkin DB: Fibroblast growth factors as angiogenesis factors: new insights into their mechanism of action. EXS 1997, 79:159-192.

23. Holvoet $\mathrm{P}$, Collen D, Van de Werf F: Malondialdehyde-modified LDL as a marker of acute coronary syndromes. JAMA 1999, 281:1718-1721.

24. Stachowiak MK, Moffett J, Joy A, Puchacz E, Florkiewicz R, Stachowiak EK: Regulation of bFGF gene expression and subcellular distribution of bFGF protein in adrenal medullary cells. J Cell Biol 1994, 127:203-223.

25. Moffett J, Kratz E, Florkiewicz R, Stachowiak MK: Promoter regions involved in density-dependent regulation of basic fibroblast growth factor gene expression in human astrocytic cells. Proc Natl Acad Sci U S A 1996, 93:2470-2475.

26. Tang D, Lu J, Walterscheid JP, Chen HH, Engler DA, Sawamura T, Chang PY, Safi HJ, Yang $\mathrm{CY}$, Chen $\mathrm{CH}$ : Electronegative LDL circulating in smokers impairs endothelial progenitor cell differentiation by inhibiting Akt phosphorylation via LOX-1. J Lipid Res 2008, 49:33-47.

27. Chang PY, Chen YJ, Chang FH, Lu J, Huang WH, Yang TC, Lee YT, Chang SF, Lu SC, Chen $\mathrm{CH}$ : Aspirin protects human coronary artery endothelial cells against atherogenic electronegative LDL via an epigenetic mechanism: a novel cytoprotective role of aspirin in acute myocardial infarction. Cardiovasc Res 2013, 99:137-145.

28. Lorenzen JM, Martino F, Thum T: Epigenetic modifications in cardiovascular disease. Basic Res Cardiol 2012, 107:245

29. Movassagh M, Vujic A, Foo R: Genome-wide DNA methylation in human heart failure. Epigenomics 2011, 3:103-109.

30. Handy DE, Castro R, Loscalzo J: Epigenetic modifications: basic mechanisms and role in cardiovascular disease. Circulation 2011 123:2145-2156.

31. Mitra S, Khaidakov M, Lu J, Ayyadevara S, Szwedo J, Wang XW, Chen C, Khaidakov S, Kasula SR, Stone A, et al: Prior exposure to oxidized low-density lipoprotein limits apoptosis in subsequent generations of endothelial cells by altering promoter methylation. Am J Physiol Heart Circ Physiol 2011, 301:H506-H513.

32. Huang $Y$, Peng $K$, Su J, Huang $Y, X u Y$, , Wang S: Different effects of homocysteine and oxidized low density lipoprotein on methylation status in the promoter region of the estrogen receptor alpha gene. Acta Biochim Biophys Sin (Shanghai) 2007, 39:19-26.

33. Chen KC, Wang YS, Hu CY, Chang WC, Liao YC, Dai CY, Juo SH: OxLDL up-regulates microRNA-29b, leading to epigenetic modifications of MMP-2/MMP-9 genes: a novel mechanism for cardiovascular diseases. FASEB J 2011, 25:1718-1728

34. Santini V, Kantarjian HM, Issa JP: Changes in DNA methylation in neoplasia: pathophysiology and therapeutic implications. Ann Intern Med 2001, 134:573-586.

35. Nakano E, Taiwo FA, Nugent D, Griffiths HR, Aldred S, Paisi M, Kwok M, Bhatt $\mathrm{P}$, Hill MH, Moat S, Powers HJ: Downstream effects on human low density lipoprotein of homocysteine exported from endothelial cells in an in vitro system. J Lipid Res 2005, 46:484-493.

36. Nagase M, Ando K, Nagase T, Kaname S, Sawamura T, Fujita T: Redox-sensitive regulation of lox-1 gene expression in vascular endothelium. Biochem Biophys Res Commun 2001, 281:720-725.
37. Nishi K, Itabe H, Uno M, Kitazato KT, Horiguchi H, Shinno K, Nagahiro S: Oxidized LDL in carotid plaques and plasma associates with plaque instability. Arterioscler Thromb Vasc Biol 2002, 22:1649-1654.

38. Tsimikas S, Brilakis ES, Miller ER, McConnell JP, Lennon RJ, Kornman KS, Witztum JL, Berger PB: Oxidized phospholipids, Lp(a) lipoprotein, and coronary artery disease. N Engl J Med 2005, 353:46-57.

doi:10.1186/1423-0127-21-11

Cite this article as: Yang et al:: Malondialdehyde mediates oxidized LDL-induced coronary toxicity through the Akt-FGF2 pathway via DNA methylation. Journal of Biomedical Science 2014 21:11.

\section{Submit your next manuscript to BioMed Central and take full advantage of:}

- Convenient online submission

- Thorough peer review

- No space constraints or color figure charges

- Immediate publication on acceptance

- Inclusion in PubMed, CAS, Scopus and Google Scholar

- Research which is freely available for redistribution 